\title{
DỨBin
}

Technological University Dublin ARROW@TU Dublin

2002-01-01

\section{Annular Planar Monopole Antennas}

\author{
Z. N. Chen \\ National University of Singapore \\ Max Ammann \\ Technological University Dublin, max.ammann@tudublin.ie \\ W.Y. W. Chia \\ National University of Singapore
}

See next page for additional authors

Follow this and additional works at: https://arrow.tudublin.ie/engschececon

Part of the Electrical and Computer Engineering Commons

\section{Recommended Citation}

Chen, Z. et al. (2002) Annular planar monopole antennas. IEE Proceedings on Microwaves, Antennas and Propagation, Vol.149, pp.200-2003. August, 2002, doi:10.1049/ip-map:20020701

This Conference Paper is brought to you for free and open access by the School of Electrical and Electronic Engineering at ARROW@TU Dublin. It has been accepted for inclusion in Conference papers by an authorized administrator of ARROW@TU Dublin. For more information, please contact arrow.admin@tudublin.ie, aisling.coyne@tudublin.ie,gerard.connolly@tudublin.ie.

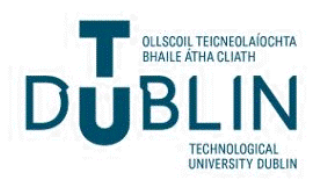




\section{Authors}

Z. N. Chen, Max Ammann, W.Y. W. Chia, and T.S. P. See

This conference paper is available at ARROW@TU Dublin: https://arrow.tudublin.ie/engschececon/9 


\title{
Annular planar monopole antennas
}

\author{
Z.N. Chen, M.J. Ammann, M.Y.W. Chia and T.S.P. See
}

\begin{abstract}
A type of annular planar monopole antenna is presented. The impedance and radiation characteristics of the monopole with different hole The measured results demonstrate that the proposed antenna is capable of providing significantly broad impedance bandwidth with acceptable radiation performance.
\end{abstract}

\section{Introduction}

Recently, a simple but powerful technique to broaden the impedance bandwidths of monopole antennas has been widely used and studied numerically and experimentally. In this manner, the radiating wire elements of monopoles are replaced with the planar elements with various shapes to increase the surface areas of the monopoles [1-10]. The radiation patterns of a square planar monopole were first presented and studied over a frequency range by Dubost and Zisler in 1976 [1]. In 1992, Honda et al. designed a circular planar monopole having an 8:1 impedance bandwidth [2]. Numerical and experimental investigations on planar monopoles of different geometrical shapes, such as the ellipse, rectangle, bow-tie, diamond and trapezoid, have since been conducted. Until now, the achieved impedance bandwidths for VSWR $=2: 1$ have usually reached about 10:1 for an elliptical planar monopole and $80 \%$ for the other planar monopoles. By means of the equivalent cylindrical monopole, some simple formulas have been developed to evaluate the frequency corresponding to the lower edge of the passband (FLEPB) $[3-5,7,10]$. Their characteristics have also been analysed by numerical methods, such as the method of moments with wire grid and triangular cell meshing [8,9]. Recently, a novel kind of monopole antenna was proposed to further enhance their impedance bandwidths $[11,12]$. With the aid of electromagnetic coupling between the planar radiating element and the excited element, the impedance bandwidths were widened dramatically.

In this paper, the impedance and radiation characteristics of annular planar monopole antennas are experimentally investigated. The effects of the circular holes concentrically cut from the circular elements of planar monopole antennas on the impedance bandwidth, the FLEPB, and the radiation patterns are first discussed. Next, the effect of the feed gaps on the FLEPB is examined. The measurements show that, as compared to a circular planar monopole without any holes, the proposed annular monopole antennas still achieve extremely broad impedance

(C) IEE, 2002

IEE Proceedings online no. 2002070

DOI: $10.1049 / \mathrm{ip}$-map:20020701

Paper first received 27th April and in revised form 8th August 2001

Z.N. Chen, M.Y.W. Chia and T.S.P. See are with the Centre for Wireless Communications, National University of Singapore, 20 Science Park Road, \#02-34/37 TeleTech Park, Singapore Science Park II, 117674, Singapore

M.J. Ammann is with the School of Electronic and Communications Engineering. Dublin Institute of Technology, Dublin 8, Ireland bandwidths, typically of the order of $>8: 1$ for both VSWR $=2: 1$ and 3:1. The introduction of the holes is shown to have little or no effect on the radiation pattern at lower frequencies and to have acceptable effects at higher frequencies. Owing to the introduction of the hole to the planar element, the weight, volume (also height), wind resistance and cost of the antenna are greatly reduced. These are desirable features, especially at low frequencies.

\section{Antennas and results}

The geometry of an annular planar monopole antenna is shown in Fig. 1. The radiating circular element is made of a thin copper sheet of radius $R=25 \mathrm{~mm}$ and vertically located above a finite-size ground plane $\left(305 \times 305 \mathrm{~mm}^{2}\right)$. The circular sheet is in the $x-z$ plane. A $50 \Omega$ coaxial probe of $0.6 \mathrm{~mm}$ radius excites the bottom of the sheet through the ground plane via an SMA connector. The feed gap between the feed point and the ground plane is denoted by $g$. A circular hole with radius $r$ is concentrically cut from the circular element.

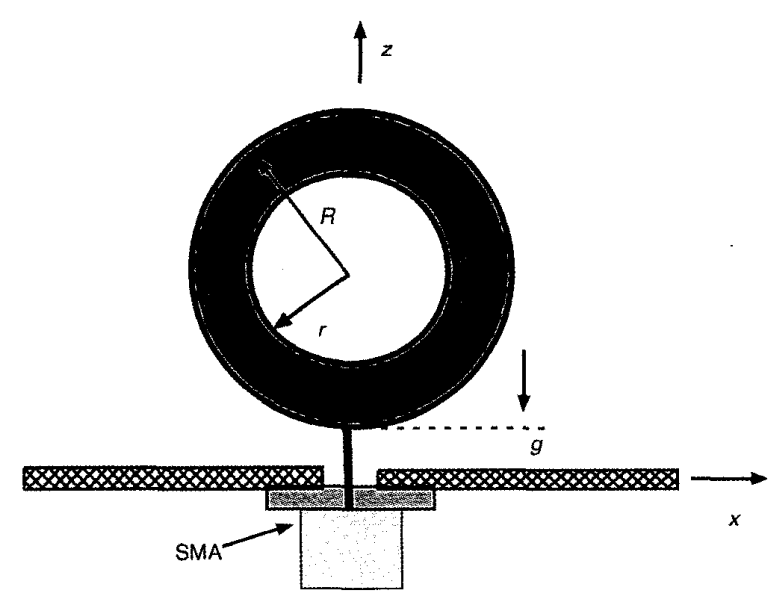

Fig. 1 Geometry of annular planar monopole antenna

The input impedance of the proposed annular monopole antenna was first measured. The impedance characteristics with respect to different parameters, such as the feed gap $g$ and the radius $r$, were examined. The achieved impedance bandwidths (BWs) and FLEPBs were obtained. As an example, the measured VSWRs for the different antennas 
are plotted in Fig. 2, where the radius $r$ is set to $0,5,10,15$ and $20 \mathrm{~mm}$ and the feed gap $g$ to $0.7,1.6$ and $2.3 \mathrm{~mm}$. The measured BWs and FLEPBs for a specific VSWR $=2: 1$

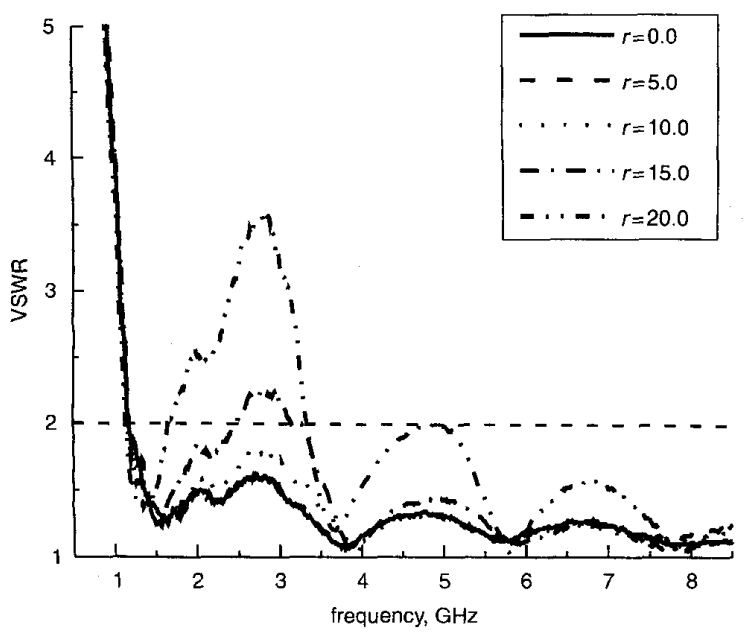

a

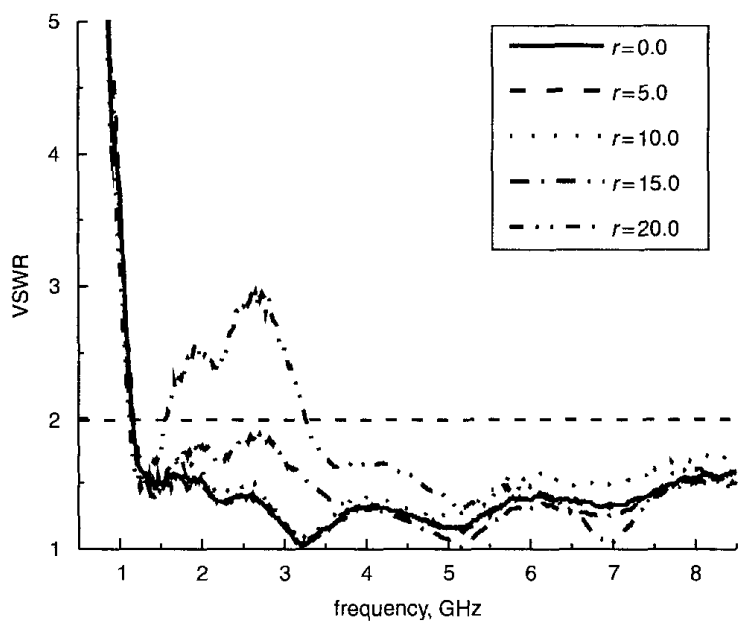

$b$

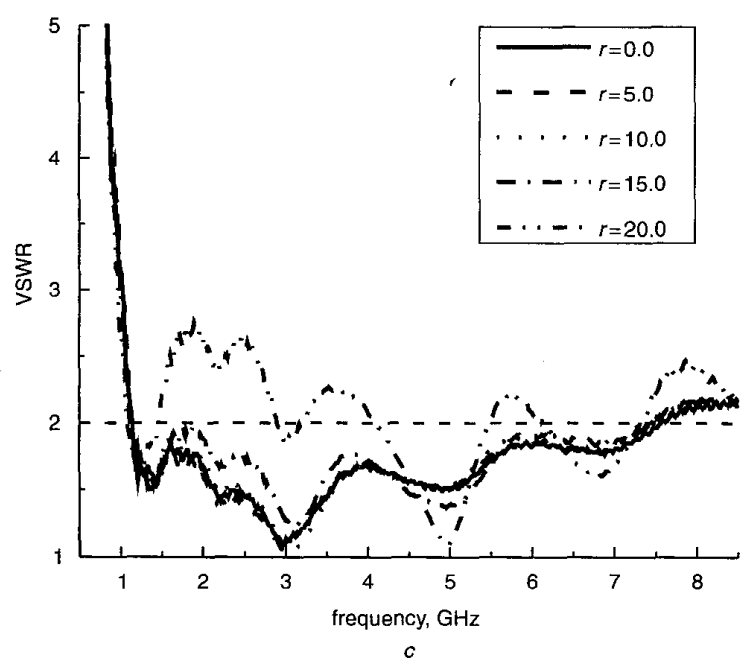

Fig. 2 Measured VSWR against frequency for different hole radii $v$ $a g=0.7 \mathrm{~mm} ; b g=1.6 \mathrm{~mm} ; c g=2.3 \mathrm{~mm}$ and 3:1 are tabulated in Table 1, where the BWs are calculated with the following formulas:

$$
\mathrm{BW}=\left\{\begin{array}{l}
2\left(f_{\text {higher }}-f_{\text {lower }}\right) /\left(f_{\text {higher }}+f_{\text {lower }}\right) \times 100 \% \\
\quad \text { for } \mathrm{BW} \leq 100 \% \\
f_{\text {higher }}: f_{\text {lower }} \\
\quad \text { for } \mathrm{BW}>100 \%
\end{array}\right.
$$

Table 1: Measured impedance bandwidth (BW) and frequency corresponding to lower edge of passband (FLEPB) with feed gaps of $g=0.7,1.6$ and $2.3 \mathrm{~mm}$

\begin{tabular}{|c|c|c|c|c|c|}
\hline \multirow{2}{*}{ Antenna } & \multirow[t]{2}{*}{$g, \mathrm{~mm}$} & \multicolumn{2}{|c|}{ VSWR $=2: 1$} & \multicolumn{2}{|c|}{ VSWR $=3: 1$} \\
\hline & & $\begin{array}{l}\text { FLEPB, } \\
\mathrm{GHz}\end{array}$ & BW & $\begin{array}{l}\text { FLEPB, } \\
\mathrm{GHz}\end{array}$ & BW \\
\hline 1 & 0.7 & 1.17 & $>8.5: 1$ & 1.07 & $>8.5: 1$ \\
\hline \multirow[t]{2}{*}{$r=0 \mathrm{~mm}$} & 1.6 & 1.15 & $>8.5: 1$ & 1.06 & $>8.5: 1$ \\
\hline & 2.3 & 1.14 & $6.72: 1$ & 1.00 & $>8.5: 1$ \\
\hline 2 & 0.7 & 1.18 & $>8.5: 1$ & 1.09 & $>8.5: 1$ \\
\hline \multirow[t]{2}{*}{$r=5 \mathrm{~mm}$} & 1.6 & 1.17 & $>8.5: 1$ & 1.06 & $>8.5: 1$ \\
\hline & 2.3 & 1.14 & $6.58: 1$ & 1.03 & $>8.5: 1$ \\
\hline 3 & 0.7 & 1.18 & $>8.5: 1$ & 1.10 & $>8.5: 1$ \\
\hline \multirow[t]{2}{*}{$r=10 \mathrm{~mm}$} & 1.6 & 1.14 & $>8.5: 1$ & 1.06 & $>8.5: 1$ \\
\hline & 2.3 & 1.14 & $6.64: 1$ & 1.00 & $>8.5: 1$ \\
\hline 4 & 0.7 & 1.17 & $72.8 \%$ & 1.08 & $>8.5: 1$ \\
\hline \multirow[t]{2}{*}{$r=15 \mathrm{~mm}$} & 1.6 & 1.14 & $>8.5: 1$ & 1.05 & $>8.5: 1$ \\
\hline & 2.3 & 1.11 & $6.83: 1$ & 1.02 & $>8.5: 1$ \\
\hline 5 & 0.7 & 1.14 & $38.3 \%$ & 1.05 & $78.6 \%$ \\
\hline \multirow[t]{2}{*}{$r=20 \mathrm{~mm}$} & 1.6 & 1.12 & $34.1 \%$ & 1.02 & $>8.5: 1$ \\
\hline & 2.3 & 1.08 & $30.6 \%$ & 0.97 & $>8.5: 1$ \\
\hline
\end{tabular}

Fig. $2 a$ shows that the antennas with a feed gap $g=0.7 \mathrm{~mm}$ exhibit a highpass response although the matching conditions for the larger radii $(r=15$ and $20 \mathrm{~mm}$ ) have become worse. In Fig. $2 b$, the VSWR increases when the feed gap $g$ increases to $1.6 \mathrm{~mm}$ although the achieved bandwidths for both VSWR $=2: 1$ and $3: 1$ are quite broad, typically more than $8: 1$ for all the hole radii except for $r=20 \mathrm{~mm}$. The highpass response feature of all the antennas disappears as the feed gap reaches $2.3 \mathrm{~mm}$. This illustrates two important points. The first is that the feed gap greatly affects the impedance characteristics. The antenna operates under good conditions as the feed gap $g$ is around $1.6 \mathrm{~mm}$. Fig. 3 shows that in general, the larger the feed gap, the lower the FLEPB. The other point is that the hole cut from the circular element also has a significant effect on the impedance matching conditions. The antennas attain remarkably broad bandwidths of $>6.5: 1$ for VSWR $=2$ $: 1$ or $>8.5: 1$ for $V S W R=3: 1$ when the radii of the holes are less than $15 \mathrm{~mm}$. Fig. 3 shows that the FLEPBs start to drop when the radius is larger than $10 \mathrm{~mm}$. It is particularly interesting to note that the antennas still possess almost the same highpass feature even when $64 \%$ of the area $(r=15$ $\mathrm{mm}$ ) has been removed from the circular element. This is useful in practical designs for applications operating at low frequencies.

The radiation patterns for antennas with different holes were also examined and are shown in Figs. 4-6. The hole radii were set at $r=0$ and $15 \mathrm{~mm}$. The tests were performed at 1.5 and $5 \mathrm{GHz}$. A feed gap of $1.6 \mathrm{~mm}$ was selected for the measurements. It can be seen from Figs. $4 a, 5 a$ and $6 a$ that the effect of introducing a hole of radius $r=15 \mathrm{~mm}$ is negligible on the radiation patterns at low frequencies. At 


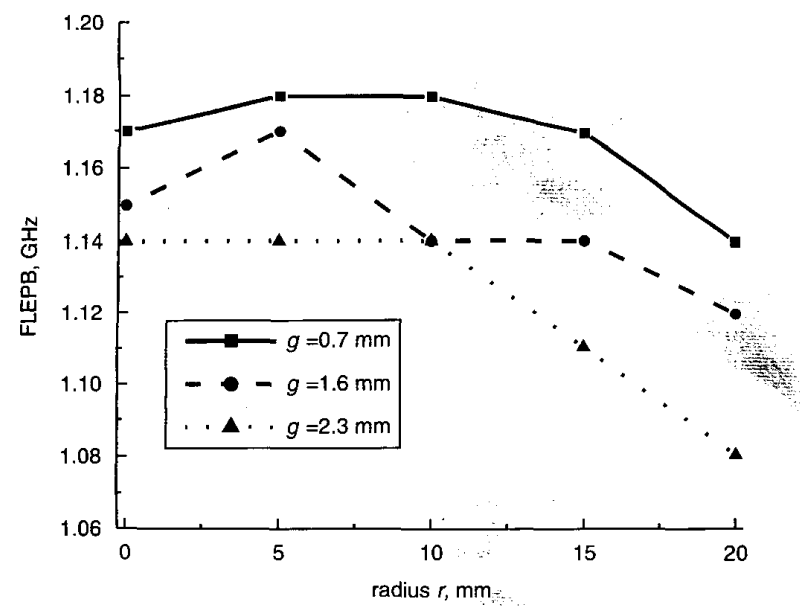

Fig. 3 Measured FLEPB against hole radit $r$ for different feed gaps $g$
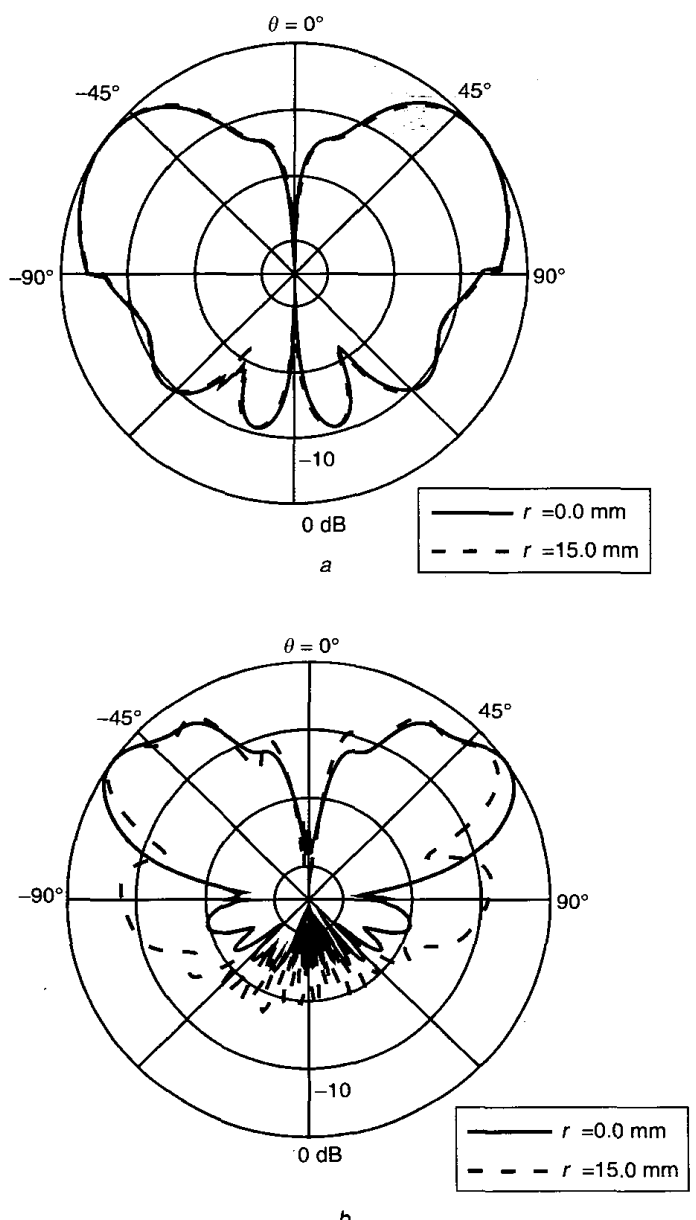

Fig. 4 Measured radiation patterns in $\phi=0^{\circ} \mathrm{cut}$ $a$ At $1.5 \mathrm{GHz} ; b$ at $5.0 \mathrm{GHz}$

these frequencies, the antenna exhibited typical omnidirectional monopolar patterns with a maximum gain of $4.8 \mathrm{dBi}$, which is constant to within $\pm 0.5 \mathrm{~dB}$ over polar angles from
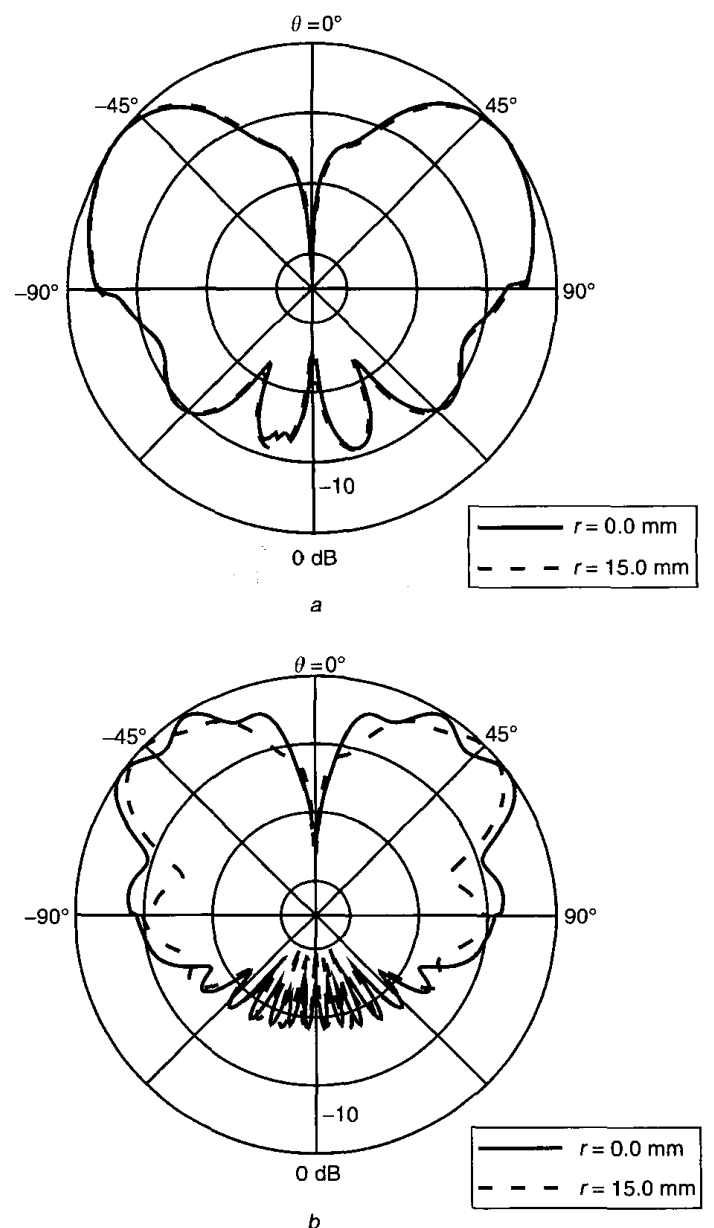

Fig. 5 Measured radiation patterns in $\phi=90^{\circ} \mathrm{cut}$ $a$ At $1.5 \mathrm{GHz} ; b$ at $5.0 \mathrm{GHz}$

$\theta=48^{\circ}$ to $\theta=63^{\circ}$. The half-power beam-widths were $48^{\circ}$ in both the $\phi=0^{\circ}$ and $\phi=90^{\circ}$ planes. The gain in the ground plane $\left(\theta=90^{\circ}\right)$ was $0.3 \mathrm{dBi}$. The introduction of the hole had no effect on the maximum gain at this frequency.

As the frequency was increased, a slight increase in directivity was observed, accompanied by a reduction in the half-power beam-widths in the vertical planes. The gain in the ground plane $\left(\theta=90^{\circ}\right)$ also fell. The effect of the hole on the patterns became more pronounced and tended to offset the gain reduction in this plane. This can be seen in Figs. $4 b$ and $5 b$, which illustrate the radiation patterns in the $\phi=0^{\circ}$ and $\phi=90^{\circ}$ cuts.

\section{Conclusions}

Experimental studies on the impedance and radiation characteristics of annular planar monopole antennas have been carried out. The results have demonstrated that the proposed antennas are still capable of offering dramatically broad impedance bandwidths and acceptable radiation patterns even when more than half of the circular element has been removed.

IEE Proc-Microw. Antennas Propag., Vol. 149, No. 4, August 2002 


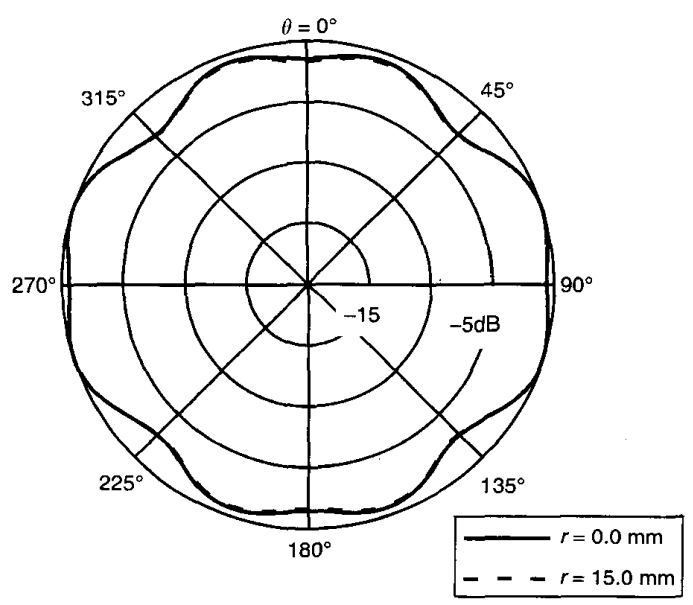

$a$

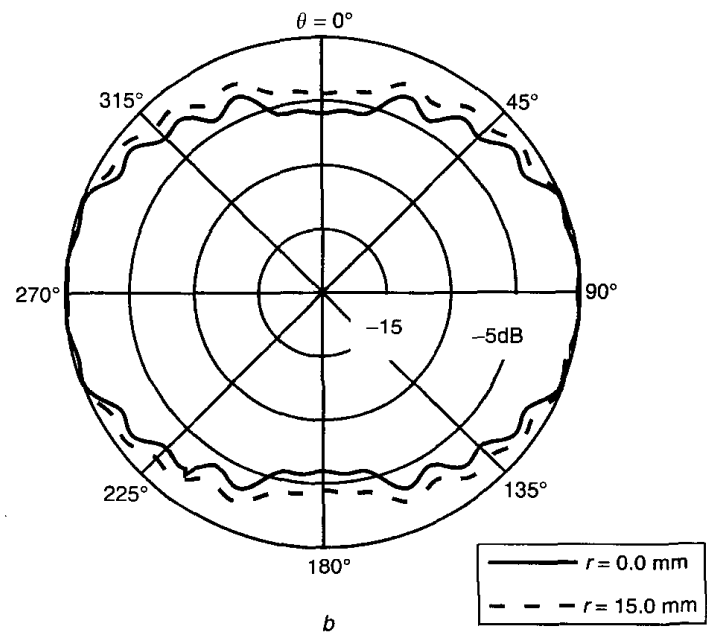

Fig. 6 Measured radiation patterns in $\theta=90^{\circ}$ plane $a$ At $1.5 \mathrm{GHz} ; b$ at $5.0 \mathrm{GHz}$

\section{References}

1 DUBOST, G., and ZISLER, S.: 'Antennas á large bande' (Masson, Paris, New York, 1976), pp. 128-129

2 HONDA, S., ITO, M., SEKI, H., and JINBO, Y.: 'A disk monopole antenna with $1: 8$ impedance bandwidth and omnidirectional radiation pattern'. International Symposium on Antennas and Propagation 1992, Sapporo, Japan, pp. 1145-1148

3 AGRAWALL, N.P., KUMAR, G., and RAY, K.P.: 'Wide-band planar monopole antenna', IEEE Trans. Antennas Propag., 1998, 46, planar monopole

4 AMMANN, M.J.: 'Square planar monopole antenna'. National Conf. Antennas \& Propagation, 1999, York, England, pp. 37-40

5 CHEN, Z.N.: 'Impedance characteristics of planar bow-tie-like monopole antennas', Electron. Lett., 2000, 36, (13), pp. 1100-1101

6 CHEN, Z.N.: 'Experiments on input impedance of tilted planar monopole antennas', Microw. Opt. Technol. Lett., 2000, 26, (3), pp. 202-204

7 CHEN, Z.N., and CHIA, M.Y.W.: 'Impedance characteristics of trapezoidal planar monopole antenna', Microw. Opt. Technol. Lett., $2000,27,(2)$, pp. $120-122$

8 BALANIS, C.A.: 'Antenna theory: analysis and design' (Wiley, New York, 1997)

9 HAMMOUD, M., POEY, P., and COLOMBEL, F.: 'Matching the input impedance of a broadband disc monopole', Electron. Lett., 1993 29, (4), pp. $406-407$

10 AMMANN, M.J.: "The pentagonal planar monopole for digital mobile terminals; bandwidth considerations and modelling'. Proceedings of 11 th IEE ICAP 2001,2 , pp. 82-85

11 CHEN, Z.N., and CHIA, M.Y.W.: 'Broadband monopole antenna with parasitic planar element', Microw. Opt. Technol. Lett., 2000, 27, (3), pp. 209-210

12 CHEN, ZN.: 'Broadband planar monopole antenna', IEE Proc. Microw. Antennas Propag., 2000, 147, (6), pp. 526-528 